\title{
Prevalence of nonmedical use of prescription-type opioids, methylphenidate, and sedative-hypnotics among university students in the south of Iran: a regression analysis
}

Abbas Abbasi-Ghahramanloo ${ }^{1,2}$, Mahmoud Khodadost ${ }^{3,2}$, Farhad Moradpour ${ }^{2,4}$, Mohammad Reza Karimirad ${ }^{5}$, Razieh Kamali ${ }^{6}$, Foroogh Ziarati $^{7}$

${ }^{1} \mathrm{PhD}$ Candidate in Epidemiology, Health Management Research Center, Baqiyatallah University of Medical Sciences, Tehran, Iran

${ }^{2} \mathrm{PhD}$ Candidate in Epidemiology, Department of Epidemiology, Faculty of Health, Iran University of Medical Sciences, Tehran, Iran

${ }^{3} \mathrm{PhD}$ Candidate in Epidemiology, Department of Epidemiology, Faculty of Health, Shahid Beheshti University of Medical Sciences, Tehran, Iran

${ }^{4} \mathrm{PhD}$ Candidate in Epidemiology, Social Determinants of Health Research Center, Kurdistan University of Medical Sciences, Sanandaj, Iran

${ }^{5}$ M.Sc. of Nursing, Lecturer, Department of Nursing, Hormozgan University of Medical Sciences, Bandar Abbas, Iran

${ }^{6}$ M.Sc. of Psychology, Lecturer, Hormozgan University of Medical Sciences, Bandar Abbas, Iran

${ }^{7}$ B.Sc. of Nursing, Department of Nursing, Hormozgan University of Medical Sciences, Bandar Abbas, Iran

Type of article: Original

\begin{abstract}
Background and aim: Nonmedical use of prescription drugs needs particular attention. The aim of this study was to determine the prevalence of prescription-type opioids, methylphenidate and sedative-hypnotics use, and related factors in university students.

Methods: In this cross-sectional study, 524 students of Hormozgan University of Medical Sciences were selected by multi-stage sampling in 2016. A self-report questionnaire had been used examining substance use, religious beliefs and parental support. The questions about substance use were prepared based on the World Health Organization Alcohol, Smoking and Substance Involvement Screening Test (WHO ASSIST). Religious beliefs were measured by Kendler's general religiosity questionnaire. Parental support was measured by the Persian version of Aneshensel and Sucoff's scale. All of the analysis was performed using Chi-square test, Fisher exact test, independent-samples t-test and binary logistic regression in SPSS 16 software. The level of significance was 0.05 .

Results: The last year prevalence of prescription-type opioids, methylphenidate and sedative-hypnotics use was $16.1 \%, 3.3 \%$, and $10.3 \%$, respectively. The final model of logistic regression indicated hookah use $(\mathrm{OR}=2.5)$, methylphenidate use $(\mathrm{OR}=4.5)$, sedative-hypnotics use $(\mathrm{OR}=2.7)$, and were associated with students' prescription-type opioids use. The protective factor was familial support $(\mathrm{OR}=0.97)$ for prescription-type opioids use. Moreover, sedative-hypnotics use $(\mathrm{OR}=5.7)$ and illicit drug use $(\mathrm{OR}=27.6)$ were associated with methylphenidate use among students.

Conclusions: The results of this study showed that the prevalence of nonmedical use of prescription drugs is considerably high among students and is in need of interventions to reduce the prevalence of these drugs in universities.
\end{abstract}

Keywords: Prescription drugs, Non-medical use, University students, Familial support, Religiosity

\section{Corresponding author:}

Mohammad Reza Karimirad, Department of Nursing, Hormozgan University of Medical Sciences, Bandar Abbas, Iran. Tel: +98.9173070811, Email: Karimiradr@yahoo.com

Received: February 26, 2018, Accepted: June 04, 2018, Published: June 2018

iThenticate screening: June 07, 2018, English editing: June 14, 2018, Quality control: June 15, 2018

This article has been reviewed / commented by four experts

Funding / research project approval: HUMS.REC.94119

Ethics approval: HUMS.REC.1394.51

(C) 2018 The Authors. This is an open access article under the terms of the Creative Commons Attribution-NonCommercialNoDerivs License, which permits use and distribution in any medium, provided the original work is properly cited, the use is non-commercial and no modifications or adaptations are made. 


\section{Introduction}

A student course is a period marked by intense academic stress as well as independence and separation from parenting supervision (1). During this period, risky behavior of adolescents and young people, especially opportunities for the use of psychotropic substances and illicit drugs will increase $(2,3)$. Subsequently, today it is considered as one of the main problems of public health. Based on a National Survey on Drugs Use and Health (NSDUH) report, non-medical use of prescriptions is growing and becoming an important part of the illicit drug use problem among university/college students (4). Because of legality, prescription drugs tend to be more easily available than other illegal drugs (5). Nonmedical use of prescription drugs needs particular attention due to the high degree of abuse potential and numerous ill-health consequences (6). For example, nonmedical consumption of prescription opioids can lead to respiratory suppression and overdose (7). Based on a systematic review, the rates of deaths from prescription opioids have increased worldwide (8). It is important to note that, nonmedical use of prescription drugs among young adults has been linked to intention to use or engage in other substances (9). The examples are psychiatric symptoms, psychiatric disorders and suicidal ideation (10). Many studies have focused on risk and protective factors of illicit drug use among young people. From those, familial support and religious beliefs have been mentioned as protective factors for illicit drug use $(11,12)$. Although several studies have examined illicit drug use among university students in Iran, there is limited information about prescription-type drug use among university students. For example, Abbasi-Ghahramanloo indicated that $4.9 \%$ of students misused prescription drugs in the last year. Also, there is limited information about the role of familial support and religious beliefs on prescription-type drug use. The goal of the present study was to assess the prevalence of prescription-type opioids, methylphenidate and sedative-hypnotics use and related factors, in a sample of Iranian university students.

\section{Material and Methods}

\subsection{Participants and procedure}

The present cross-sectional study was conducted in 2016 in Hormozgan using multi stage random sampling. First, the proportion of students in each school was considered as stratum. Then, randomly chosen classes were considered as the clusters. Finally, a number of classes were selected in each school and all of the members of the selected class were recruited. Before asking students to fill out the questionnaire, students were given information on how to fill them out, the anonymity and the objective of the study, and also the voluntary nature of the study, by the research team. Students were asked not to include any personal information on the questionnaires. In the final step, pens with same color were distributed among participants to gain their trust.

\subsection{Measures}

\subsubsection{Risk-taking behaviors}

For obtaining information about drug use, students completed a self-administrated questionnaire that was prepared earlier in another study (13). The questions about substance use were prepared based on the World Health Organization Alcohol, Smoking and Substance Involvement Screening Test (WHO ASSIST) in regard to the situation of substance use in Iran. The validity of the mentioned questionnaire had been done by a group of researchers in another study (13). In addition, the validity of the questionnaire was assessed by pre testing the scale among Master of Public Health students. The questions aimed to obtain information on cigarette smoking, hookah use, prescription-type opioid use, methylphenidate and sedative-hypnotic (barbiturates and benzodiazepines) use, illicit drug use, having extramarital sex, as well as demographic information. For different substances and extramarital sex, lifetime, last year and last month intervals were asked from students.

\subsubsection{Religious beliefs}

For measuring religious beliefs, we used Kendler's general religiosity questionnaire $(14,15)$. This questionnaire has 5- point scaling: $1=$ completely disagree, $2=$ disagree, $3=$ neutral, $4=$ agree and $5=$ completely agree. The lowest and highest scores of this questionnaire are 28 and 140 respectively. It should be noted that higher scores indicate higher religious beliefs. The internal consistency of the scale was estimated to be 0.97 .

\subsubsection{Parental support}

For measuring parental support, we used Aneshensel and Sucoff's 13- item scale (16). This questionnaire has 5point Likert type scaling: $1=$ completely disagree, $2=$ disagree, $3=$ neutral, $4=$ agree and $5=$ completely agree. The lowest and highest scores of this questionnaire are 13 and 65 respectively. It should be noted that higher scores indicate higher parental support. An estimated reliability coefficient of 0.86, was computed by Cronbach's Alpha Coefficient. 


\subsection{Statistical analysis}

For assessing the relationship of the prescription-type opioids, methylphenidate, and sedative-hypnotics with other variables, the last year of use was used in the statistical analysis. Chi-square and Fisher's exact tests were used to assess the relationship of qualitative variables with prescription-type opioids, methylphenidate, and sedativehypnotics status. Independent-samples t-test was performed to compare differences of the means of quantitative variables among prescription-type opioids, methylphenidate, and sedative-hypnotics users and non-users. For assessing the relationship of all related factors with prescription-type opioids, methylphenidate and sedativehypnotics, binary logistic regression was used for each outcome. All analyses were performed using SPSS version 16 (SPSS Inc., Chicago, Illinois, USA) and the statistically significant level was considered as 0.05 .

\subsection{Research ethics}

This study was approved by the Ethics Committee of Hormozgan University of Medical Sciences (Ref. no: HUMS.REC.1394.51). Before distributing the questionnaires, explanations were presented by the research team regarding the purposes of the study and the voluntary nature of the students in the study. Then, written informed consent was obtained. Participants were also asked not to include their personal information in the questionnaire. All the questionnaires were completed anonymously to ensure the confidentiality of participants' information.

\section{Results}

The mean age of the students was $23.0 \pm 4.2$ years (range: $18-47)$. The majority of the sample were male (58.2\%) and only $19.8 \%$ of the sample were married. Table 1 presents the percentage of 'Yes' response to the use of prescription-type opioids, methylphenidate and sedative-hypnotics use in different time intervals. It is apparent from this table that among 524 students, $109(20.8 \%), 84(16.1 \%)$ and $25(9.9 \%)$ had used prescription-type opioids in their lifetime, past year and past month respectively. This table indicates that the lifetime, past year and past month prevalence of methylphenidate use was found to be $5.4 \%, 3.3 \%$, and $2.3 \%$ respectively. Also, the prevalence of sedative-hypnotics use in the three mentioned time intervals was 15.6, 10.3 and $6.1 \%$. Table 2 presents the demographic characteristics and risk variables of the total sample, as well as the conditional distribution of prescription-type opioids, methylphenidate and sedative-hypnotics use at each level of the variables. Also, the mean and standard deviation of the age of the students, the score of familial support and score of religious beliefs were presented in this table.

Table 3 shows the results of the binary logistic regression. This table indicates that living in a dormitory $(\mathrm{OR}=0.50)$ and single house $(\mathrm{OR}=0.07)$ in comparison to a parental home, last year hookah use $(\mathrm{OR}=2.5)$, last year methylphenidate use $(\mathrm{OR}=4.5)$, last year sedative-hypnotics use $(\mathrm{OR}=2.7)$ and having higher score of familial support $(\mathrm{OR}=0.97)$ were factors associated with students' prescription-type opioid use. After adjusting for other factors, results of the final analysis indicate that last year sedative-hypnotics use $(\mathrm{OR}=5.7)$ and lifetime illicit drug use $(\mathrm{OR}=27.6)$ were associated with students' methylphenidate use. Also, past year hookah use $(\mathrm{OR}=4.9)$, last year prescription-type opioids $(\mathrm{OR}=2.2)$ and last year methylphenidate use $(\mathrm{OR}=7.5)$ were associated with sedativehypnotics.

Table 1. Prevalence of Prescription-type opioids, Methylphenidate and Sedative-hypnotics by gender.

\begin{tabular}{|l|l|l|l|l|}
\hline Variable & & Male * & Female * & Total * \\
\hline Prescription-type opioids & Lifetime use & $59(27.4)$ & $49(16.1)$ & $109(20.8)$ \\
\cline { 2 - 5 } & Last year use & $45(20.9)$ & $38(12.5)$ & $84(16.1)$ \\
\cline { 2 - 5 } & Last month use & $26(12.1)$ & $25(8.2)$ & $52(9.9)$ \\
\hline \multirow{3}{*}{ Methylphenidate } & Lifetime use & $17(7.9)$ & $11(3.6)$ & $28(5.4)$ \\
\cline { 2 - 5 } & Last year use & $11(5.1)$ & $6(2.0)$ & $17(3.3)$ \\
\cline { 2 - 5 } & Last month use & $8(3.7)$ & $4(1.3)$ & $12(2.3)$ \\
\hline Sedative-hypnotics & Lifetime use & $44(20.5)$ & $38(12.5)$ & $82(15.6)$ \\
\cline { 2 - 5 } & Last year use & $27(12.6)$ & $27(8.9)$ & $54(10.3)$ \\
\cline { 2 - 5 } & Last month use & $15(7.0)$ & $17(5.6)$ & $32(6.1)$ \\
\hline & *Data are presented as n (\%) & \\
\hline
\end{tabular}


http://www.ephysician.ir

Table 2. Demographic characteristics and correlated variables by last year use of "prescription-type opioids", "Methylphenidate", and "Sedative-hypnotics" in a sample of Iranian students in 2016.

\begin{tabular}{|c|c|c|c|c|c|c|c|}
\hline \multirow{2}{*}{\multicolumn{2}{|c|}{ Characteristics }} & \multicolumn{2}{|c|}{$\begin{array}{l}\text { Prescription-type } \\
\text { opioids }\end{array}$} & \multicolumn{2}{|c|}{ Methylphenidate } & \multicolumn{2}{|c|}{ Sedative-hypnotics } \\
\hline & & n (\%) & p-value & $\mathrm{n}(\%)$ & p-value & $\mathrm{n}(\%)$ & p-value \\
\hline \multirow[t]{2}{*}{ Gender } & Male & $38(12.5)$ & 0.010 & $6(2.0)$ & 0.046 & $27(8.9)$ & 0.177 \\
\hline & Female & $45(20.9)$ & & $11(5.1)$ & & $27(12.6)$ & \\
\hline \multirow[t]{2}{*}{ Marital status } & Single & $63(15.3)$ & 0.458 & $12(2.9)$ & 0.331 & $42(10.2)$ & 0.903 \\
\hline & Married & $19(18.3)$ & & $5(4.8)$ & & $11(10.6)$ & \\
\hline \multirow[t]{3}{*}{ Living in } & Parental home & $26(21.0)$ & 0.297 & $2(1.6)$ & 0.042 & $11(8.9)$ & $<0.001$ \\
\hline & Dormitory & $50(13.7)$ & & $11(3.0)$ & & $31(8.4)$ & \\
\hline & Single house & $6(21.4)$ & & $3(10.7)$ & & $11(39.3)$ & \\
\hline \multirow[t]{2}{*}{ Smoking (last year) } & No & $61(13.7)$ & $<0.001$ & $7(1.6)$ & $<0.001$ & $33(7.4)$ & $<0.001$ \\
\hline & Yes & $23(30.3)$ & & $10(13.2)$ & & $21(27.6)$ & \\
\hline \multirow[t]{2}{*}{ Hookah use (last year) } & No & $49(12.0)$ & $<0.001$ & $6(1.5)$ & $\mid<0.001$ & $24(5.9)$ & $<0.001$ \\
\hline & Yes & $35(30.4)$ & & $11(9.5)$ & & $30(25.9)$ & \\
\hline \multirow[t]{2}{*}{ Alcohol use (last year) } & No & $63(13.9)$ & $<0.001$ & $7(1.5)$ & $<0.001$ & $34(7.5)$ & $<0.001$ \\
\hline & Yes & $21(31.3)$ & & $10(14.7)$ & & $20(29.4)$ & \\
\hline \multirow{2}{*}{$\begin{array}{l}\text { Prescription-type opioids } \\
\text { (last year) }\end{array}$} & No & - & - & $7(1.6)$ & $<0.001$ & $32(7.3)$ & $<0.001$ \\
\hline & Yes & - & & $10(11.9)$ & & $22(26.2)$ & \\
\hline \multirow{2}{*}{$\begin{array}{l}\text { Methylphenidate (last } \\
\text { year) }\end{array}$} & No & $74(14.7)$ & $<0.001$ & - & |- & $42(8.3)$ & $<0.001$ \\
\hline & Yes & $10(58.8)$ & & - & & $12(70.6)$ & \\
\hline \multirow{2}{*}{$\begin{array}{l}\text { Sedative-hypnotics (last } \\
\text { year }\end{array}$} & No & $62(13.3)$ & $<0.001$ & $5(1.1)$ & $<0.001$ & - & - \\
\hline & Yes & $22(40.7)$ & & $12(22.2)$ & & - & \\
\hline \multirow[t]{2}{*}{ Illicit drugs } & No & $62(13.4)$ & $<0.001$ & $3(0.6)$ & $<0.001$ & $32(6.9)$ & $<0.001$ \\
\hline & Yes & $21(41.2)$ & & $13(25.5)$ & & $21(41.2)$ & \\
\hline \multirow{2}{*}{$\begin{array}{l}\text { Extra marital sex(last } \\
\text { year) }\end{array}$} & No & $66(14.2)$ & $<0.001$ & $8(1.7)$ & $<0.001$ & $41(8.8)$ & 0.001 \\
\hline & Yes & $17(34.7)$ & & $8(16.3)$ & & $12(24.5)$ & \\
\hline \multicolumn{2}{|l|}{ Age (year); Mean (SD) } & $23.7(4.6)$ & 0.08 & $24.6(4.44)$ & 0.09 & $24.0(4.9)$ & 0.06 \\
\hline \multirow{2}{*}{\multicolumn{2}{|c|}{ Score of religious beliefs; Mean (SD) }} & $113.3(20.0)$ & 0.014 & $121.5(16.3)$ & 0.455 & $115.0(18.02)$ & 0.204 \\
\hline & & $50.1(9.6)$ & $<0.001$ & $45.4(14.6)$ & 0.001 & $50.3(11.1)$ & 0.005 \\
\hline
\end{tabular}

Table 3. Logistic regression analysis of the association between last year use of "prescription-type opioids",

"Methylphenidate" and "Sedative-hypnotics" and their correlated factors in a sample of Iranian students 2016

\begin{tabular}{|c|c|c|c|c|c|c|c|c|c|c|}
\hline \multirow{2}{*}{\multicolumn{2}{|c|}{ Variables }} & \multicolumn{3}{|c|}{ Prescription-type opioids ${ }^{\mathrm{a}}$} & \multicolumn{3}{|c|}{ Methylphenidate $^{\mathrm{b}}$} & \multicolumn{3}{|c|}{ Sedative-hypnotics ${ }^{\mathrm{c}}$} \\
\hline & & OR & $95 \% \mathrm{CI}$ & p-value & OR & $95 \% \mathrm{CI}$ & p-value & OR & $95 \% \mathrm{CI}$ & p-value \\
\hline \multirow[t]{3}{*}{ Living in } & Parental home & Ref & - & - & - & - & - & - & - & - \\
\hline & Dormitory & 0.50 & $0.27-0.92$ & 0.027 & - & - & - & - & - & - \\
\hline & Single house & 0.07 & $0.008-0.72$ & 0.075 & - & - & - & - & - & - \\
\hline \multicolumn{2}{|c|}{ Hookah use (last year) } & 2.5 & $1.3-4.7$ & 0.005 & - & - & - & 4.9 & $2.4-9.8$ & $<0.001$ \\
\hline \multicolumn{2}{|c|}{ Prescription-type opioids(last year) } & - & - & - & - & - & - & 2.2 & \begin{tabular}{|l|}
$1.01-$ \\
5.03
\end{tabular} & 0.046 \\
\hline \multicolumn{2}{|c|}{ Methylphenidate (last year) } & 4.5 & $1.0-18.8$ & 0.040 & - & - & - & 7.5 & \begin{tabular}{|l|}
$1.9-$ \\
30.2
\end{tabular} & 0.004 \\
\hline \multicolumn{2}{|c|}{ Sedative-hypnotics (last year) } & 2.7 & $1.2-6.2$ & 0.019 & 5.7 & $1.4-23.2$ & 0.016 & - & - & - \\
\hline \multicolumn{2}{|c|}{ Illicit drugs (life time) } & - & - & - & 27.6 & 6.4-118.6 & $<0.001$ & - & - & - \\
\hline \multicolumn{2}{|c|}{ Familial support } & 0.97 & $0.94-0.99$ & 0.037 & - & - & - & - & - & - \\
\hline
\end{tabular}

a: Variables entered on step 1: gender, age, marital status, living place, smoking, hookah use, alcohol use, methylphenidate, sedativehypnotics, illicit drug use, extra marital sex, religious beliefs and familial support. B: Variables entered on step 1: gender, age, marital status, living place, smoking, hookah use, alcohol use, prescription-type opioids, sedative-hypnotics, illicit drug use, extra marital sex, religious beliefs and familial support. c: Variables entered on step 1: gender, age, marital status, living place, smoking, hookah use, alcohol use, prescription-type opioids, methylphenidate, illicit drug use, extra marital sex, religious beliefs and familial support. 


\section{Discussion}

In the present study, the lifetime, past year and past month prevalence of prescription-type opioid use were determined to be $20.8 \%, 16.1 \%$, and $9.9 \%$ respectively. According to the 2016 world drug report, it was estimated that in 2014, the annual prevalence of opioid use among the population aged 15-64 was 0.7 and $0.42 \%$ in the world and Asia respectively (14). In the United States, based on National Survey on Drug Use and Health (NSDUH) data among people aged 18-25 years old, the lifetime, past year and past month prevalence of use of prescription opioids were 18.2, 9.6 and 3.6\% respectively in 2001 (6). However, in 2015, the prevalence of using prescription opioids in the last year was $37.8 \%$. Also in the last year, $4.7 \%$ of participants misused prescription opioids and $0.8 \%$ reported having use disorder (17). In the latest Monitoring The Future (MTF) study (18), lifetime, past year and past month prevalence of narcotics other than heroin (including methadone, morphine, codeine, etc.) were 6.6, 3.3 and 1.3\%. A national study from Iran indicated that $49.3 \%$ of Iranian adults had used this type of drug at least once in the last year in 2014 (19). Some previous studies from Iran reported the separated prevalence of each non-medical use of opioid drugs among university students. For example, the prevalence of last month morphine use had been reported as $0.36 \%$ among Gilan University of Medical Sciences (Gilan Province, Iran) (20). Another study from Hamadan showed that $9.5 \%$ of college students had used tramadol in the last month (21). Overall, it seems that the prevalence of using prescription-type opioids is high among Iranian students. Some differences among results of studies can be attributed to the definition of prescription opioids and the place of study. Also in Iran, in comparison to illicit drugs, prescription opioids have a low social stigma.

Results from the present study also indicated that the lifetime, past year and past month prevalence methylphenidate use was 5.4, 3.3 and 2.3\%. In a Monitoring The Future (MTF) study in the US, 2\% of the participants had used methylphenidate in the past year in 2015 (18). A qualitative study among university students in Tehran (capital of Iran) showed that unlike other drugs that are used recreationally, methylphenidate is used for enhancing learning abilities and academic achievements. This drug can be easily used and is considered to be stigma free (22). A smaller study among medical students from Iran showed that $8.7 \%$ of the participants had used methylphenidate at least once in their lifetime (23). Another study among residents of clinical specialties of Tehran University of Medical Sciences indicated that lifetime, past year and past month prevalence of methylphenidate use was $48 \%$, $23 \%$ and $6.6 \%$ respectively $(24)$. It seems that there is no negative attitude toward methylphenidate use among some of the medical university students. For example, Khademi and Shariat showed that $20 \%$ of the residents had a positive attitude toward methylphenidate (24). This can be seen as a warning of the start of a methylphenidate use epidemic among young people in Iranian universities. In this study, the prevalence of sedative-hypnotics use in a lifetime, past year and past month was obtained to be 15.6, 10.3 and 6.1\% respectively. In an MTF study (18), nonprescription use of sedatives in a lifetime, last year and last month was reported to be $4.4 \%, 2.3 \%$ and $1 \%$ in 2015 . This study also indicated that the prevalence of tranquilizers in the three mentioned time intervals were reported to be $7.8 \%, 4.3 \%$, and $1.6 \%$ respectively. Regarding European countries, in a recent European School Survey Project on Alcohol and Other Drug (ESPAD) study (25), it was found that on average, 6\% of the students reported lifetime non-medical use of tranquilizers or sedatives, ranging from the lowest $(2 \%)$ in Moldova to the highest (17\%) in Poland. Due to the different definitions of the sedative-hypnotics, the best comparisons are not possible. But the rates of this drug usage in this study seem to be high and needs attention.

One of the effective approaches in drug-related research is considering the co-occurrence nature of these behaviours. Some prior studies were able to show co-occurrence of risky behaviours (26-28). Our findings indicated that prescription-type opioids, methylphenidate, and sedative-hypnotics use are strongly associated with each other as well as all risk taking behaviours. Brooks at al. emphasized that involvement in one risky behaviour is related to engagement in other risky behaviours (29). Co-occurrence of high risk behaviours in our study further highlights the importance of implementing co-morbid substance use prevention programs among university students. Numerous researches have pointed to the inhibiting role of religious beliefs and familial support in engaging in high risk behaviours $(15,30-32)$. The result of the present study indicated that the mean score of religious beliefs was significantly associated with prescription-type opioid use. Also, the mean score of familial support was significantly associated with prescription-type opioids, methylphenidate and sedative-hypnotics use. However, only the mean score of familial support remains significant for the prescription-type opioid use in the logistic model.

\section{Limitations}

The limitations of this study were: 1) causality could not be assessed due to the cross sectional nature of the study design, and 2) underreporting of drug use could not be ruled out because the study relied on self-report data. 


\section{Conclusions}

In this study, we present the prevalence of non-medical use of prescription-type opioids, methylphenidate, and sedative-hypnotics, and determined some of related factors. Overall, our findings suggest that the prevalence of prescription type drug use is considerably high among our study samples. For exact estimations and determining the affecting factors, longitudinal studies are required. The results of the present study can be used for planning and evaluating interventions among Hormozgan medical university sciences by considering the protective and risk factors.

\section{Acknowledgments:}

The present article was financially supported by Hormozgan University of Medical Sciences (Grant number: HUMS.REC.94119). The authors would like to acknowledge Mostafa Salari and Leila Bordbar for their help in the data collection and data entry to the computer.

\section{Conflict of Interest:}

There is no conflict of interest to be declared.

\section{Authors' contributions:}

All authors contributed to this project and article equally. All authors read and approved the final manuscript.

\section{References:}

1) Gardner M, Steinberg L. Peer influence on risk taking, risk preference, and risky decision making in adolescence and adulthood: an experimental study. Developmental psychology. 2005; 41(4): 625. doi: 10.1037/0012-1649.41.4.625. PMID: 16060809.

2) Sommet A, Ferrières N, Jaoul V, Cadieux L, Soulat JM, Lapeyre-Mestre M, et al. Use of drugs, tobacco, alcohol and illicit substances in a French student population. Therapie. 2012; 67(5): 429-35. doi: 10.2515/therapie/2012056. PMID: 23241252.

3) Locke GW, Shilkret R, Everett JE, Petry NM. Interpersonal guilt and substance use in college students. Substance abuse. 2015; 36(1): 113-8. doi: 10.1080/08897077.2014.885482. PMID: 24579980.

4) Han B, Compton WM, Blanco C, Crane E, Lee J, Jones CM. Prescription Opioid Use, Misuse, and Use Disorders in U.S. Adults: 2015 National Survey on Drug Use and Health. Ann Intern Med. 2017; 167(5): 293-301. doi: 10.7326/m17-0865.

5) Martins SS, Ghandour LA. Nonmedical use of prescription drugs in adolescents and young adults: not just a Western phenomenon. World Psychiatry. 2017; 16(1): 102-4. doi: 10.1002/wps.20350. PMID: 28127929.

6) Zacny J, Bigelow G, Compton P, Foley K, Iguchi M, Sannerud C. College on Problems of Drug Dependence taskforce on prescription opioid non-medical use and abuse: position statement. Drug and alcohol dependence. 2003; 69(3): 215-32. PMID: 12633908.

7) Upadhyaya HP, Kroutil LA, Deas D, Durell TM, Van Brunt DL, Novak SP. Stimulant Formulation and Motivation for Nonmedical Use of Prescription Attention - Deficit/Hyperactivity Disorder Medications in a College - Aged Population. The American journal on addictions. 2010; 19(6): 569-77. doi: 10.1111/j.1521-0391.2010.00078.x. PMID: 20958854.

8) Martins SS, Sampson L, Cerdá M, Galea S. Worldwide prevalence and trends in unintentional drug overdose: a systematic review of the literature. Am J Public Health. 2015; 105(11): e29-49. doi: 10.2105/AJPH.2015.302843. PMID: 26451760, PMCID: PMC4605170.

9) Zahlan L, Ghandour L, Yassin N, Afifi R, Martins SS. Double trouble: Exploring the association between waterpipe tobacco smoking and the nonmedical use of psychoactive prescription drugs among adolescents. Drug and alcohol dependence. 2014; 145: 217-23. doi: 10.1016/j.drugalcdep.2014.10.020. PMID: 25456333.

10) Kuramoto SJ, Chilcoat HD, Ko J, Martins SS. Suicidal ideation and suicide attempt across stages of nonmedical prescription opioid use and presence of prescription opioid disorders among US adults. J Stud Alcohol Drugs. 2012; 73(2): 178-84. PMID: 22333325, PMCID: PMC3281977.

11) Rezaie F, Noroozi A, Armoon B, Farhoudian A, Massah O, Sharifi H, et al. Social determinants and hepatitis $\mathrm{C}$ among people who inject drugs in Kermanshah, Iran: socioeconomic status, homelessness, and sufficient syringe coverage. Journal of Substance Use. 2016: 1-5. doi: 10.1080/14659891.

12) Mehrabi M, Eskandarieh S, Khodadost M, Sadeghi M, Nikfarjam A, Hajebi A. The Impact of Social Structures on Deviant Behaviors: The Study of 402 High Risk Street Drug Users in Iran. J Addict. 2016; 2016: 6891751. doi: 10.1155/2016/6891751. PMID: 27994907, PMCID: PMC5138462. 
13) Amin-Esmaeili M, Rahimi-Movaghar A, Yunesian M, Sahimi-Izadian E, Moinolghorabaei M. Trend of smoking among students of Tehran University of Medical Sciences: results from four consecutive surveys from 2006 to 2009. Med J Islam Repub Iran. 2013; 27(4): 168-78. PMID: 24926177. PMCID: PMC4011406.

14) Kendler KS, Liu XQ, Gardner CO, McCullough ME, Larson D, Prescott CA. Dimensions of religiosity and their relationship to lifetime psychiatric and substance use disorders. Am J Psychiatry. 2003; 160(3): 496503. doi: 10.1176/appi.ajp.160.3.496. PMID: 12611831.

15) Farhadinasab A, Allahverdipour H, Bashirian S, Mahjoub H. Lifetime pattern of substance abuse, parental support, religiosity, and locus of control in adolescent and young male users. Iranian Journal of Public Health. 2008; 37(4): 88-95.

16) Aneshensel CS, Sucoff CA. The neighborhood context of adolescent mental health. Journal of health and social behavior. 1996: 293-310. doi: 10.2307/2137258. PMID: 8997886.

17) Han B, Compton WM, Blanco C, Crane E, Lee J, Jones CM. Prescription opioid use, misuse, and use disorders in US adults: 2015 National Survey on Drug Use and Health. Annals of Internal Medicine. 2017; 167(5): 293-301. doi: 10.7326/M17-0865. PMID: 28761945.

18) Johnston LD, O'Malley PM, Bachman JG, Schulenberg JE, Miech RA. Monitoring the Future national survey results on drug use, 1975-2015: Volume 2, College students and adults ages 19-55. Ann Arbor: University of Michigan Institute for Social Research; 2015.

19) Rahimi-Movaghar A, Sharifi V, Motevalian A, Amin-Esmaeili M, Hadjebi A, Rad Goodarzi R. Iranian National Mental Health Survey: prevalence, severity and costs of mental disorders and service utilization (IranMHS). Tehran: Mehrsa; 2014.

20) Zarrabi H, Najafi K, Kafi M, Shirazi M. Substance use among students of Guilan University of Medical Sciences in Iran in 2005-2006. Acta Medica Iranica. 2009; 47(6): 473-8.

21) Fathi Y, Bashirian S, Barati M, Hazavei SMM. Tramadol abuse status and related factors among three college students in Hamadan. Sci. J. of Hamadan University of Medical Sciences. 2012; 19(3): 23-9.

22) Rahimi Movaghar A, Khastoo G, Moinolghorabaei M, Yunesian M, Sadeghi AR. Use of stimulant substances among university students in Tehran: a qualitative study. Iranian journal of psychiatry and behavioral Sciences. 2011; 5(2): 32-42. PMID: 24644445, PMCID: PMC3939960.

23) Habibzadeh A, Alizadeh M, Malek A, Maghbooli L, Shoja MM, Ghabili K. Illicit methylphenidate use among Iranian medical students: prevalence and knowledge. Drug design, development and therapy. 2011; 5: 71. doi: 10.2147/DDDT.S13818. PMID: 21340040.

24) Khademi L. Prevalence of nonmedical use of methylphenidate (Ritalin) in residents. Iranian Journal of Psychiatry and Clinical Psychology. 2013; 19(1): 20-7.

25) Hibell B, Guttormsson U, Ahlström S, Balakireva O, Bjarnason T, Kokkevi A, et al. The 2015 ESPAD report: Substance use among students in 36 European countries: Swedish Council for Information on Alcohol and other Drugs Stockholm; 2015.

26) Benotsch EG, Snipes DJ, Martin AM, Bull SS. Sexting, substance use, and sexual risk behavior in young adults. J of Adolescent Health. 2013; 52(3): 307-13. doi: 10.1016/j.jadohealth.2012.06.011. PMID: 23299017.

27) Abbasi-Ghahramanloo A, Fotouhi A, Zeraati H, Rahimi-Movaghar A. Prescription drugs, alcohol, and illicit substance use and their correlations among medical sciences students in Iran. Int J High Risk Behav Addict. 2015; 4(1): e21945. doi: 10.5812/ijhrba.21945. PMID: 25821750.

28) Snipes DJ, Benotsch EG. High-risk cocktails and high-risk sex: examining the relation between alcohol mixed with energy drink consumption, sexual behavior, and drug use in college students. Addictive behaviors. 2013; 38(1): 1418-23. doi: 10.1016/j.addbeh.2012.07.011. PMID: 23006245.

29) Brooks FM, Magnusson J, Spencer N, Morgan A. Adolescent multiple risk behaviour: an asset approach to the role of family, school and community. Journal of Public Health. 2012; 34(suppl_1): i48-56. doi: 10.1093/pubmed/fds001. PMID: 22363031.

30) Gryczynski J, Ward BW. Social norms and the relationship between cigarette use and religiosity among adolescents in the United States. Health Education \& Behavior. 2011; 38(1): 39-48. doi: 10.1177/1090198110372331. PMID: 21189421.

31) Wills TA, Resko JA, Ainette MG, Mendoza D. Role of parent support and peer support in adolescent substance use: a test of mediated effects. Psychology of Addictive Behaviors. 2004; 18(2): 122. doi: 10.1037/0893-164X.18.2.122. PMID: 15238054.

32) Allahverdipour H, Abbasi-Ghahramanloo A, Mohammadpoorasl A, Nowzari P. Cigarette smoking and its relationship with perceived familial support and religiosity of university students in Tabriz. Iranian journal of psychiatry. 2015; 10(3): 136. PMID: 26877746. 